\title{
Peter Panero fotografiado en un yate con
}

Blancanieves

Ningún rastro de los enanos

\section{Alessandro Obinu}

\section{(2) OpenEdition}

\section{Journals}

Edición electrónica

URL: http://journals.openedition.org/agedor/648

DOI: 10.4000 /agedor.648

ISSN: 2104-3353

\section{Editor}

Laboratoire LISAA

Referencia electrónica

Alessandro Obinu, "Peter Panero fotografiado en un yate con Blancanieves », LÂAge d'or [En línea],

7 | 2014, Publicado el 01 marzo 2014, consultado el 20 abril 2019. URL : http://

journals.openedition.org/agedor/648; DOI : 10.4000/agedor.648 


\title{
Alessandro OBINU
}

Università degli Studi di Torino, Scuola di Dottorato in Lingue e Letterature Moderne.

\section{Peter Panero fotografiado en un yate con Blancanieves. Ningún rastro de los enanos}

Résumé : Leopoldo María Panero erre entre les vers de sa poésie accompagné d'une foule de personnages de son enfance et d'une vaste trajectoire littéraire. Personnages qui, une fois devant le miroir, s'avèrent être les fragments du moi du poète, les masques qui décomposent et composent en même temps une identité multiple. Au cours de ce cheminement poétique, l'œuvre de Panero peut être étudiée parallèlement à ses réflexions sur la traduction, à ses per-versions. Une poétique comme une tentative constante de se-traduire, comme une traversée aveugle des interlignes du moi dans une quête infernale de l'identité. Et le masque comme un instrument traductologique de soi.

Mots-clés : Blanche-Neige - Pirandello - Masque - Perversion - Traduction - Narcisse - Georges Bataille

Resumen: Leopoldo María Panero anda por los versos de su poesía acompañado por una muchedumbre de personajes, de la infancia y de su vasto recorrido literario. Personajes que, llegados frente a un espejo, resultan ser las fracciones del yo del poeta, máscaras que descomponen y a la vez componen una identidad múltiple. En este andar poético, la obra de Panero puede ser analizada paralelamente a sus reflexiones traductológicas, a sus per-versiones. Su poética como una tentativa continua de traducir-se, un atravesar a oscuras lo interlineado del yo en esa búsqueda infernal de la identidad. Y la careta como un instrumento traductológico del sí.

Palabras clave: Blancanieves - Pirandello - Máscara - Perversión - Traducción - Narciso Georges Bataille

\author{
Locura es estar ausente \\ Humo es todo lo que queda de mí \\ En la página que no bay \\ Cae al suelo mi figura \\ Y libre de mi se mueve \\ Elpapel de pura ausencia.
}

Leopoldo María Panero

$\longrightarrow$

1 realismo me da la impresión de un error. Solamente la violencia se sustrae al sentimiento de miseria de las experiencias realistas. Sólo la muerte y el deseo tienen la fuerza que oprime, que quita el respiro. Solamente el exceso del deseo y de la muerte permite alcanzar la verdad [...] Se abre delante de la especie humana una dúplice perspectiva: por un lado la perspectiva del placer violento, del horror y de la 
muerte - precisamente la de la poesía - por otro lado, en sentido opuesto, la perspectiva de la ciencia y del mundo real de la utilidad. Solamente lo útil, lo real, tienen un carácter de seriedad. No tenemos el derecho de preferirle la seducción: la verdad tiene derechos sobre nosotros. Aún más, ella tiene todos los derechos sobre nosotros. No obstante podemos, y más: debemos responder a algo que, sin ser Dios, es más fuerte que todos los derechos: este imposible al que sólo podemos acceder olvidando la verdad de todos aquellos derechos, aceptando su desaparición ${ }^{1}$.

Palpar lo imposible es un gesto que Leopoldo María Panero ha estado cumpliendo, a su pesar, desde el principio. Desde cuando con una no velada preocupación el lejano Padre Palomar le confiaba a la madre del poeta, Felicidad Blanc, que Leopoldo «puede ser todo o nada» ${ }^{2}$. En aquel continuo balanceo entre el Todo y la Nada se desarrolla, además de la vida, gran parte de su palabra poética. De su resistencia a lo real. La nada que tanto preocupaba a Padre Palomar no es, en el ánimo del poeta, una dimensión espacial vacía, oscura. Volviendo al ya mencionado Georges Bataille, uno de los ingredientes del mejor Panero, lo podemos identificar justamente en el lugar del exceso del deseo, del placer violento y de la muerte. De lo poético. Algo que en Panero muy a menudo adquiere la forma de la multiplicidad que tiende, a través del rayo de lo real, hacia la búsqueda de la identidad.

Uno de los puntos fundamentales de esta búsqueda es la presencia constante del espejo y de la máscara; figuras e instrumentos esenciales para la puesta en escena de otros yo en el intento del auto-reconocimiento. Una toma de conciencia tormentosa que Panero explicita en un tipo de escritura que, en palabras de Maurice Blanchot, podríamos definir interrumpida. Así lo escribe Blanchot:

Cómo escribir de tal modo que la continuidad de la escritura pueda dejar intervenir, fundamentalmente, la interrupción como sentido y la ruptura como forma? [...] cualquier lenguaje donde se trate de interrogar y no de responder es un lenguaje ya interrumpido, más aún, un lenguaje en que todo empieza por la decisión (o la distracción) de un vacío inicial. ${ }^{3}$

La poesía del poeta español es una poesía que cuestiona. Al igual que para cuestionar está puesto el espejo delante del sujeto. Acerca de este aspecto es interesante notar la relación puesta en evidencia por el estudioso Túa Blesa que, en el texto dedicado a Leopoldo María Panero, retoma las palabras de Theodore Ziolkowski en Imágenes encantadas acerca de la clasificación de los espejos mágicos principales. Ziolkowski enfoca la atención sobre tres espejos, el catoptromántico, un espejo útil para pedir informaciones, el espejo de doblaje donde la imagen reflejada surge como si se tratara del doble de quien se pone ante él y, por último, el espejo penetrable, en el que quien se mira puede adentrarse, sobrepasarlo para vivir y experimentar el reflejo de su mundo. Los dos segundos espejos manejan imágenes simbólicas: el yo y un modelo alternativo del mundo 4 .

En esta clasificación lo que principalmente se deduce es el afán por la búsqueda de una propia identidad. Un camino lleno de monstruos, rostros y máscaras, miedos necesarios para acercarse, quizás solamente a la idea, a la existencia real del hombre. Miedos que se hacen presentes en toda la obra y la vida de Leopoldo María Panero.

\footnotetext{
${ }^{1}$ De la introducción del texto Lo imposible, BATAILLE Georges, Madrid, Arena Libros, 2001.

${ }^{2}$ CHAVARRI, Jaime, El Desencanto, Guión cinematográfico, Madrid, Elías Querejeta Ediciones, 1976, p. 67.

${ }^{3}$ BLANCHOT, Maurice, La conversación infinita, Madrid, Arena Libros, 2008, p. 8.

${ }^{4}$ BLESA, Túa, Leopoldo María Panero, el último poeta, Madrid, Valdemar, 1995, p. 45.
} 
Cuando en el 1979 se publica Narciso en el acorde último de las flautas, la referencia de Panero al mito clásico de Narciso y al alcance simbólico de la figura reflejada se hace explícita y cargada tanto de positividad como de negatividad. Escribe García Fernández acerca del paralelismo Narciso-Panero:

Conciencia de la otredad, onanismo estético, o simplemente conciencia desolada. En cualquier caso, la contemplación íntima de un suicidio. Narciso «en el acorde último de las flautas», será al final la lucidez oracular de un niño que se negó a crecer [...] elegís de lo bello y sobre todo muerte. ${ }^{5}$

En 2001 en Poemas para un suicidamiento, encontramos los versos siguientes: «Tengo cinco poemas / escritos contra mí mismo / contra mi máscara y deseo / de ser verdad, como la muerte / como el sapo obsceno de la muerte /que escupe aún un tardío poema [...]»

Y aún, en 2008 en Conjuros contra la vida, vuelve en su prosa el espejo:

Todo comienza mirándose al espejo [...] Me gustaría apuñalar al ser, apuñalar a Dios, hundir el cuchillo en su carne de hembra, sepultar el universo [...] Yo, yo, yo: yo no soy ya un hombre, soy un monstruo, alguien que no sabe quién es [...] Y le hablaba al espejo, y recorría las calles perseguido por mi yo, y en la escritura hallé un palacio abandonado: yo era más bello que el diablo, y hoy soy sólo un palacio en vano. ${ }^{7}$

Era en 1979, pero también en 2001 y en 2008; se podría seguir añadiendo versos y vivencias para comprobar aún mejor la infinita pesadilla del poeta ante la vida y la muerte.

Una muerte o una vida que antes de hacerse realidad dejan fluir en el espejo «un abanico de rostros diferentes entre sí aunque todos ellos hagan referencia a un único ser: estos son las máscaras. Con el término máscara no nos referimos sólo a los diferentes Yo, sino también a los personajes y sujetos con los que Panero se identificaba» ${ }^{8}$. Así lo estipula con tino Michela Ferrante en su ensayo sobre Panero.

En definitiva, leyendo los versos del poeta nos enfrentamos con un Yo quebrantado y complejo, hecho de fragmentos, de elementos distintos que mantienen una relación entre ellos, que se pueden disgregar y recomponer en una nueva agregación para obtener como resultado otra nueva personalidad, como en una unión alquímica. Así que se puede decir, con la ayuda de Pirandello, que más personas viven y actúan a un mismo tiempo, cada una por su cuenta, en el mismo individuo.

Vivos y que actúan. Alteridad entonces. La máscara en Panero no es un instrumento simbólico detrás del cual esconderse sino todo lo contrario: se amplifica.

En Relatos clínicos, Freud y Jung utilizan el término «descomposición» justamente cuando abordan la problemática de la descomposición de la personalidad. No es arrogancia asociarlo al término, y por ende a la idea, de la amplificación. Dos términos que podríamos definir como siameses y que se alimentan del mismo respiro puesto que lo que se considera unidad, descompuesta, deshecha, sacará a la luz los elementos individuales de aquel conjunto orgánicamente constituido. Cada uno de los elementos es vida de por sí.

\footnotetext{
${ }^{5}$ FERRANTE, Michela, Narciso, la maschera nello specchio:la ricerca dell'identità in Leopoldo María Panero, in Tropelías, Revista de la literatura y literatura comparada, a cura di Túa Blesa, Zaragoza, 1998-99, p. 194.

${ }^{6}$ PANerO, Leopoldo María, Poemas para un suicidamiento, in Poesía completa (2000-2010), Ed. Túa Blesa, Madrid, Visor Libros, 2012, p. 103.

7 PANERO, Leopoldo María, Conjuros contra la vida, in Poesía completa (2000-2010), op.cit., p. 483.

8 FERRANTE, Michela, Narciso, "La maschera nello specchio:la ricerca dell’identità in Leopoldo María Panero», in Tropelías, Revista de la literatura y literatura comparada, a cura di Túa Blesa, Zaragoza, 1998-99, p. 194.
} 
Descomponer es por lo tanto añadir, amplificar una o infinitas identidades nuevas. Una o infinitas conciencias nuevas, personalidades. Es lo que sucede con Panero, descompuesto, amplificado y en compañía de otros personajes, facetas del yo que, de recomponerse, pueden generar la unidad primaria generadora: Leopoldo María Panero. O, para penetrar a fondo en su complejidad poética, quedan Leopoldo, María y Panero.

Para comprender y podernos introducir en la muchedumbre de los personajes resultarán útiles los versos del poema «Le bon pasteur (Haikù)»

Es duro el trabajo de las pesadillas,

es duro

arrastrar de día el carro de las marionetas,

de noche; y ser una de ellas

mañana, cuando abran los ojos

para no ver

que la bailarina de cuerda danzando entre ellas

mueve ella misma el resorte. ${ }^{9}$

Uno de los personajes más emblemáticos que entran en esta escena bailando es, sin lugar a dudas, Peter Pan. En el poemario Tarzán Traicionado (1967), se cita un epígrafe que es un indicio fundamental: «Son morto ch'ero bambino». Freud ya se había dado cuenta de que los adultos que viven en una eterna fuga de una realidad compleja y dramática, muy a menudo, no encuentran otra posibilidad de salvación sino en el refugio dorado y despreocupado de la infancia. Una regresión del adulto al estado de niñez, época que no ha sido aún corrompida por la sociedad encarnada en la familia y la escuela. Panero dirá acerca del colegio que es «una institución penal en la que lo que nos enseñan es a olvidar la infancia. Yo me he rebelado siempre contra $[\ldots]$ esa colonización» ${ }^{10}$.

En 1984 el psicólogo junguiano, Dan Kiley, habla de un verdadero síndrome que aferra al individuo y lo aprisiona entre el hombre en el que no quiere convertirse y el niño que ya no puede seguir siendo.

Panero, inconsciente de lo que Kiley elaboraría, aun menos de lo que Freud y Jung habían escrito, resucita en sus versos las sombras fugaces de una vida en la que todo era posible. Dirá el poeta que «las alucinaciones del loco son en el niño una forma natural de la percepción».

Ocurre un acontecimiento luctuoso que el poeta representa con la máscara de Blancanieves en «Blancanieves se despide de los siete enanos»:

Los espejos silenciosos, ahora, qué grotescos, envenenados peines, manzanas, maleficios, qué olor a cerrado, ahora [...] uno tras otro los árboles se derrumban. Está en venta el jardín de los cerezos. ${ }^{11}$

Mueve el poeta la mano como un niño en señal de despedida y se aleja para siempre de la infancia, la época en que la vida ignora la muerte. Como nos sugirió Ziolkowski, existe

\footnotetext{
9 PANERO, Leopoldo María, Narciso en el acorde último de las flautas, in Poesía completa (1970-2000), Ed. Túa Blesa, Madrid, Visor Libros, 2010, p. 188.

${ }^{10}$ CHAVARRI, Jaime, El Desencanto, Guión cinematográfico, op.cit., p. 71.

${ }^{11}$ PANERO, Leopoldo María, Tarzán traicionado, in Poesía completa (1970-2000), op.cit., p. 62.
} 
un espejo que no devuelve la imagen sino que se abre para ser cruzado, y es eso lo que aparece en versos que desvelan esa intención del poeta:

Morir sí, aquí, donde todo es nieve o silencio

Que mi pecho ardiente expire tras de un beso a lo que es solo aire

Dejadme entonces besar este astro apagado

Traspasar el espejo y llegar así adonde ni siquiera el suspiro es posible. ${ }^{12}$

Busca una resurrección, otro mundo posible en cuanto se rechaza la realidad presente, una huida para ser otro sujeto en otro contexto, otra realidad. Una tentativa que parece surcar el mar para llegar a la isla de Utopía, donde todo funciona y donde quizá se pueda encontrar la serenidad. Una esperanza que, probablemente, Leopoldo María Panero nunca concretizará. En 2007 acaba así un poema:

Para poder adorar el recuerdo

El psicoanalista recuerda por mí

Que yo jamás viví

Despierto como un ciervo

Encerrado en el cieno doloroso de mi memoria

Allá donde únicamente está la gloria. ${ }^{13}$

La imagen que aquí surge está ausente de un camino futuro y no hay, quizás, más espejos para cruzar, el recuerdo domina trágicamente la escena.

Esta continua búsqueda de la verdad y de la identidad más profunda, lleva a Panero a enfrentarse no solamente con otros mundos posibles o imaginados una vez cruzado el espacio-tiempo del espejo, sino también con su propia imagen que se mueve en ese cristal. Acerca de este aspecto es fundamental la figura de William Wilson en el poema «Ann Donne», Donne que, como nos lo recuerda Túa Blesa, es el protagonista de un relato de Edgar Allan Poe de 1839. William Wilson es un estudiante que se siente acosado por otro compañero de estudios, un homónimo, William Wilson. Y no es sólo un homónimo. Comparte la misma fisionomía, nació en el mismo día, se viste como él y tiene una voz terriblemente parecida. Y muy a menudo le reprocha, con tono paternal, su estilo de vida basado en los excesos, el juego, la bebida y las orgías. Durante una fiesta se desafían en un duelo en el que el protagonista, William Wilson, derrotará a su homónimo matándole para darse cuenta, justo en ese momento, al estar delante de un espejo y escuchar una sentencia:

Has vencido y me entrego. Pero a partir de ahora tú también estás muerto... muerto para el mundo, para el cielo y para la esperanza. En mí existías... y observa esta imagen, que es la tuya, porque al matarme te has asesinado tú mismo! ${ }^{14}$

En Panero como en Poe, este doble es una presencia inquietante que lleva ineluctablemente a la muerte. Es la negación del amor concebido como imposibilidad. Surge claramente el mito de Narciso, cuyo nombre es ahora William Wilson.

\footnotetext{
12 Ibid, p. 69.

13 PANERO, Leopoldo María, Versos esquizofrénicos, in Poesía Completa (2000-2010), op.cit., p. 340.

${ }^{14}$ BLESA Túa, Leopoldo María Panero, El Último Poeta, op.cit., p. 54.
} 
Tantas veces tus pasos, William Wilson,

Tantas veces tus pasos he creído escuchar

Estos pasos que son el Eco de mis pasos,

Esta sombra que es la sombra de mi sombra.

$[\ldots]$

No es verdad William Wilson

WILLIAM WILSON NO EXISTE

O al menos no es Aquel que nos salvará de la Ceniza

Pues es él mismo quien nos conduce a la Ceniza. ${ }^{15}$

William Wilson máscara de Panero. Y el poema entero es el emblema de aquel lenguaje interrumpido mencionado antes, «no es verdad, no existe, o al menos no es Aquel, es él mismo ». La creación del doble es para el poeta una patente toma de conciencia de la muerte, una realidad no aceptada y un intento de resurgir en otro lugar.

Otro ejemplo en el que Panero establece un vínculo entre el doble y la muerte es «Destruktion Ficticia » en Teoría (1973):

La sin nombre, la de los muchos nombres, y ninguno, $[\ldots]$ y al otro lado, no ya el cuervo sobre el busto de Palas, es decir, un doble fondo en ausencia de un fondo, sino un jardín a la vez público y privado, y otra redención (que no fuera ésta) de nuestra soledad, de nuestra unicidad, por intermedio de la duplicidad. ${ }^{16}$

Rechazada la unicidad, queda una redención esperada por medio de la duplicidad. Al fondo, la muerte, la sin sombra.

Llegados a este punto del artículo, considero fundamental relacionar dos elementos aparentemente lejanos enfocando la atención sobre la poética de Panero, en especial las primeras obras, es decir Por el camino de Swann, Asi se fundó Carnaby street (1970), Teoría (1973), Narciso en el acorde último de las flautas (1979), Last River together (1980), o sea los poemarios donde la imagen de una personalidad quebrantada aparece con fuerza, con su importante y controvertido período de traductor.

La clave de las traducciones panerescas hay que buscarla en el término amplificatio. La alteración del texto será una marca distintiva del Panero traductor que nos lleva a reflexionar sobre la descomposición-amplificación del Yo propuesta anteriormente. Panero será radical a tal punto que se ganará las acusaciones de ser un criminal de la traducción. Criminal porque per-vertido, porque «perversión es la única traducción, fiel y ello mediante el adulterio, la infidelidad ${ }^{17}$. Trabaja las traducciones hundiéndose en lo oculto de la interlínea, lugar donde el texto toma la forma del infinito, un vacío a la espera de ser surcado y llenado. Escribe Panero:

En esa Grieta del texto; pero no para agrietarlo, sino precisamente para rellenarlo, perfeccionar, terminar el texto original (una vez más, no para siempre, ya que una nueva traducción, o una simple lectura, encontrará otras Grietas, que llenarán a su vez, nuevas palabras, nuevos sentidos, viejos por cuanto nacidos - el infinito que es el texto - porque el texto no será nunca el Texto, será siempre su ausencia. ${ }^{18}$

\footnotetext{
${ }^{15}$ PANERO, Leopoldo María, Tarzán Traicionado, in Poesía Completa (1970-2000), op.cit., p. 72-73

16 PANERO, Leopoldo María, "Destruktion Ficticia », Teoría, ibid., p. 80.

${ }^{17}$ BLESA, Túa, Traducciones/Perversiones, Madrid, Visor Libros, 2011, p. 30.

${ }^{18}$ Ibid, p. 30-31.
} 
Así la traducción será, consecuentemente, una verdadera creación literaria. En estas dos artes, poesía y traducción, manejadas por el poeta, es posible entrever una continuidad. Leopoldo María Panero se arroja, a través de sus mismos versos a la vacuidad del Yo intentando, no sin ejercer violencia, traducirse. Se puede analizar la obra poética de Panero viéndola como una constante auto-traducción del Yo. El Panero traductor y el Panero poeta se confunden en los versos creados, sean los del mismo poeta o aquellos no visibles de Carroll o Lewis y traducidos hábilmente por Panero. Es de este modo como el poeta se adentra en un mundo oscuro, vagando entre las interlíneas del Yo; un lugar habitado por las propias multiplicidades. La máscara es para Panero un instrumento traductológico de su propio ser en un instante vivo de auto-observación. A lo mejor inconsciente. Escribe Freud:

La existencia de semejante instancia susceptible de tratar al resto del yo como si fuera un objeto, o sea la posibilidad de que el hombre sea capaz de auto-observación, permite que la vieja representación del doble adquiera un nuevo contenido y que se le atribuya una serie de elementos: en primer lugar, todo aquello que la autocrítica considera perteneciente al superado narcisismo de los tiempos primitivos.

Pero no sólo este contenido ofensivo para la crítica yoica puede ser incorporado al doble, sino también las posibilidades de nuestra experiencia que no han hallado realización y que la imaginación no se resigna a abandonar, todas aspiraciones del yo que no pudieron cumplirse a causa de adversas circunstancias exteriores, así como todas las acciones volitivas coartadas que han producido la ilusión del libre albedrío. ${ }^{19}$

Auto-traduciéndose, Panero se vuelve Peter-Panero, sentado en las hombreras de Blancanieves o insinuándose como un ratón en las más sórdidas y apestosas fisuras de un manicomio: «yo creo que uno puede cambiar perfectamente y que el espíritu del hombre es siempre libertad pura porque es pura vacuidad. ¿No?»»

Sin embargo, de los enanos no hay rastro.

${ }^{19}$ BLESA, Túa, Leopoldo María Panero, El último poeta, op.cit., p. 57.

${ }^{20}$ CHAVARRI, Jaime, El Desencanto, Guión cinematográfico, op.cit., p. 87. 